\title{
In Situ TEM Observation of MgO Nanorod Growth
}

Albert G. Nasibulin, ${ }^{* \dagger}{ }^{\dagger}$ Litao Sun, ${ }^{\star}$ Sampsa Hämäläinen, ${ }^{\dagger}$ Sergey D. Shandakov $,{ }^{\dagger}, \perp$ Florian Banhart," and Esko I. Kauppinen ${ }^{\dagger, \#}$

${ }^{\dagger}$ NanoMaterials Group, Department of Applied Physics and Center of New Materials,

Helsinki University of Technology, Puumiehenkuja 2, 02150, Espoo, Finland, ${ }^{*}$ Key Laboratory of

MEMS of Ministry of Education, Southeast University, Sipailou 2, Nanjing 210096, China, Institut de

Physique et Chimie des Matériaux, 23 rue du Loess, Université de Strasbourg, 67034 Strasbourg, France,

${ }^{\perp}$ Laboratory of Carbon NanoMaterials, Department of Physics, Kemerovo State University,

Kemerovo 650043, Russia, and ${ }^{\#}$ VTT Biotechnology, Biologinkuja 7, 02044, Espoo, Finland

Received August 24, 2009; Revised Manuscript Received November 5, 2009

\begin{abstract}
The controlled growth of $\mathrm{MgO}$ nanorods was investigated under electron irradiation in transmission electron microscopes at accelerating voltages from 120 to $300 \mathrm{kV}$ in the temperature range from -175 to $610{ }^{\circ} \mathrm{C}$. The nanorod growth on the surface of $\mathrm{MgO}$ crystals was induced by $\mathrm{Au}, \mathrm{Pt}, \mathrm{Ni}$, or Co particles of $2-4 \mathrm{~nm}$ in size. The nanorods were grown up to $8 \mathrm{~nm}$ after 5-30 min of electron irradiation time with beam current densities of $100-600 \mathrm{~A} / \mathrm{cm}^{2}$. The mechanism of nanorod formation and growth is explained on the basis of electrostatic interactions between positive ions of $\mathrm{MgO}$ species and negatively charged metal particles.
\end{abstract}

Quasi one-dimensional nanometer-sized structures have recently attracted significant attention due to their unique properties and wide potential applications in electronic and optic devices, in highly sensitive biological and gas sensors, in catalysis, etc. ${ }^{1-3} \mathrm{Up}$ to now, much attention has been paid to various oxide nanowires and nanorods, which exhibit a rich variety of physical properties, including ferromagnetism, ferroelectric properties, and superconductivity, and might add further functionalities to devices based on quasi onedimensional nanostructures. Magnesium oxide, a typical wide-band gap insulator, has been extensively used as an additive in refractory experiments due to its high thermal stability, as a paint product, and as a component in high temperature superconductors. ${ }^{4} \mathrm{MgO}$ has been utilized as a protective film for plasma display screens and included in brake linings, owing to its favorable thermomechanical properties. Extruded magnesia has been applied as a protective sheath in aggressive environments.

$\mathrm{MgO}$ crystals were widely used as single crystal substrates for thin film growth due to the small mismatch in lattice parameters with many metals and metal oxides. $\mathrm{MgO}$ nanoparticles are typically smooth cubic crystals that are transparent to the electron beam in a transmission electron microscope (TEM) and thereby have been utilized as a substrate for high resolution TEM investigations of particles and clusters. ${ }^{5-10}$ During TEM investigations of the most stable Au particle shape on the surface of $\mathrm{MgO}$ crystals, Ajayan and Marks noticed the effect of decoupling of the particles from the substrate attributed to the increase in the particle/substrate interfacial energy. ${ }^{5-7}$ Giorgio examined the formation of $\mathrm{MgO}$ terraces during studies of electron-beam-induced transformation of gold particles. ${ }^{11}$ Kizuka observed the formation and subsequent surface structural evolution of the $\mathrm{MgO}$ clusters on the surface of Au particles. ${ }^{11}$

Here, we report for the first time that in addition to $\mathrm{CVD}^{11-15}$ and pulsed laser deposition ${ }^{16-18}$ techniques, quasi

*To whom all correspondence should be addressed: Telephone: +35850 3397538. Fax: +358 451 3517. E-mail: albert.nasbulin@hut.fi. one-dimensional nanometer $\mathrm{MgO}$ structures can be grown under electron beam irradiation of $\mathrm{MgO}$ crystals covered by different metals at temperatures as low as $-175^{\circ} \mathrm{C}$. We report the results of in situ examination of $\mathrm{MgO}$ nanorod formation in a TEM under a wide range of parameters: at accelerating voltages from 120 to $300 \mathrm{kV}$ and at temperatures from $-175 \mathrm{C}$ to $610{ }^{\circ} \mathrm{C}$. As a material promoting the growth, we have examined $\mathrm{Au}, \mathrm{Pt}, \mathrm{Ni}, \mathrm{Co}$, and $\mathrm{Fe}$ sputtered on the surface of $\mathrm{MgO}$ substrates. We present a growth mechanism of $\mathrm{MgO}$ rods, which can be explained on the basis of electrostatic interactions between metal particles and a substrate.

Cubic $\mathrm{MgO}$ nanoparticles were synthesized by burning 5-10 mm sized $\mathrm{Mg}$ granules at ambient conditions. ${ }^{19}$ The combustion product was collected by passing a carbon-coated copper TEM grid through the smoke about $2-3 \mathrm{~cm}$ above the burning granule. Electron diffraction patterns (EDPs), energy dispersive X-ray spectroscopy (EDX), and powder XRD analyses confirmed the formation of $\mathrm{MgO}$ (Supporting Information, Figure S1). The existence of $\mathrm{Mg}(\mathrm{OH})_{2}, \mathrm{MgCO}_{3}$, and $\mathrm{Mg}_{3} \mathrm{~N}_{2}$, which can be formed due to reaction with water vapor, carbon dioxide, and nitrogen, can be ruled out. Statistical measurements of $\mathrm{MgO}$ particles from TEM images revealed the $\log$-normal particle size distribution with the geometric mean diameter of $37.7 \mathrm{~nm}$ and the standard deviation of 1.91 (Supporting Information, Figure S2). Au, Pt, Ni, $\mathrm{Co}$, or Fe were sputtered on TEM grids with predeposited $\mathrm{MgO}$ particles using an Agar sputter coater (model 108A) under $0.05 \mathrm{mbar}$ of Ar pressure at $20 \mathrm{~mA} \mathrm{dc}$ at the distance from the metal target of $37 \mathrm{~mm}$. Sputtering time was varied from 5 to $25 \mathrm{~s}$.

Electron irradiation and imaging were carried out in three different microscopes (FEI Tecnai F-30, Philips CM-200 and CM12) with an acceleration voltage ranging from 120 to $300 \mathrm{kV}$. A heating stage (Philips) and a cooling stage (Gatan) were used to keep the specimens at different temperatures during the irradiation experiments. Selected $\mathrm{MgO}$ particles were subjected to intense electron irradiation with beam current densities of $100-600 \mathrm{~A} / \mathrm{cm}^{2}$ and monitored in situ with high resolution by taking images in certain time intervals. 


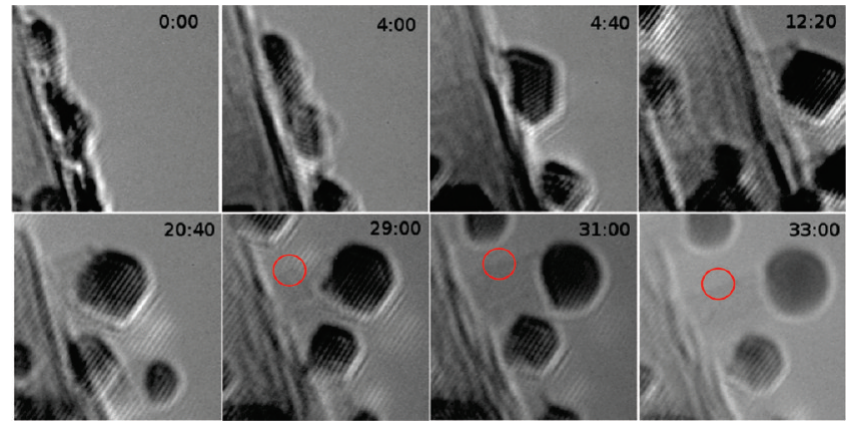

Figure 1. Growth of $\mathrm{MgO}$ nanorods in a TEM at room temperature $(200 \mathrm{kV})$. The time from the start of the irradiation is displayed on each image (in min:sec). As can be seen, diffusion of Pt on the surface (first 3 images) occurred much more quickly than the actual growth. Beam current density: $200 \mathrm{~A} / \mathrm{cm}^{2}$. Each image represents an area of $9.2 \times 9.2 \mathrm{~nm}^{2}$. The red circles show the edge of a $\mathrm{MgO}$ nanorod.

For $\mathrm{MgO}$ nanorod growth, we applied $\mathrm{Pt}, \mathrm{Au}, \mathrm{Ni}$, and $\mathrm{Co}$. However, Fe sputtered on the surface of $\mathrm{MgO}$ particles did not result in the growth of nanorods (Supporting Information, Figures S4-S6). The statistical measurements of the diameters of $\mathrm{MgO}$ nanorods grown using $\mathrm{Pt}$ and $\mathrm{Au}$ particles revealed that nanorods had mean diameters of 2.2 and $2.4 \mathrm{~nm}$, respectively (Supporting Information, Figure S3). As an example, Figure 1 shows the formation of $\mathrm{MgO}$ nanorods under an electron beam growing from $\mathrm{Pt}$ particles on the surface of cubic $\mathrm{MgO}$ particles at room temperature with the accelerating voltage of $200 \mathrm{kV}$ and current density of approximately $200 \mathrm{~A} / \mathrm{cm}^{2}$. A capped $\mathrm{MgO}$ nanorod is seen to start growing from the Pt particle after irradiation for $12 \mathrm{~min}$. The $\mathrm{MgO}$ nanorod keeps growing as the irradiation continues. Depending on the intensity of the electron beam, the growth of nanorods was observed after a 5-30 min irradiation time. Metal particles on the surface of $\mathrm{MgO}$ induced the growth of $\mathrm{MgO}$ nanorods with the maximum length of $8 \mathrm{~nm}$.

It is worth noting that there is an epitaxial relationship between $\mathrm{MgO}$ and metal particles. Moreover, the nanorods grow only in the direction family of $\langle 200\rangle$. No influence of the electron beam direction on the direction of the nanorods was found. Figure 2 shows the starting moment of the $\mathrm{MgO}$ nanorod growth. Before nanorod growth, the lattices of $\mathrm{Pt}$ particles become aligned according to the $\mathrm{MgO}$ substrate. The process of nanorod growth starts only after the rearrangement of the metal particles on the substrate. The epitaxial relationship is preserved during the nanorod growth, as can be seen in Figure 3. The nanorod growth termination is usually associated with the fact that metal particles lose their crystallographic features and as a result their epitaxial relationship with $\mathrm{MgO}$ nanorods and take the spherical form.

The mechanism of the nanorod formation can be explained on the basis of an electrostatic repulsion-attraction mechanism. Under electron beam irradiation, $\mathrm{MgO}$ particles are charged positively. ${ }^{12}$ The process of charging is related to a high secondary electron emission coefficient of $\mathrm{MgO}^{20}$ and Auger electron emission. ${ }^{21}$ In addition to positive ions of $\mathrm{Mg}$ and $\mathrm{MgO}$ molecules, $\mathrm{O}^{+}$emerges according to the Auger process based on the Knotek-Feibelman mechanism. ${ }^{12}$ The secondary electron emission yield for metals, however, is $<1$ at high energies. ${ }^{21}$ Also, there is a probability of metal particles to be negatively charged by trapping secondary electrons emitted from $\mathrm{MgO}$ particles. Therefore, $\mathrm{MgO}$ particles are charged positively whereas the metal particles might possess negative charges (Figure 4).

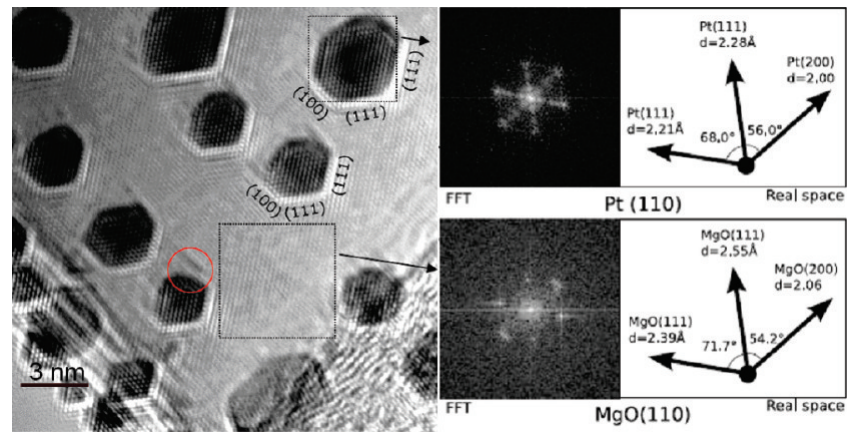

Figure 2. Facets of the Pt particles when the $\mathrm{MgO}$ nanorod growth is just initiated. The image views both lattices in the (110) direction. The red circle shows the edge of a $\mathrm{MgO}$ nanorod. It is worth noting that the lattices of the $\mathrm{Pt}$ particles and the $\mathrm{MgO}$ cube are aligned.

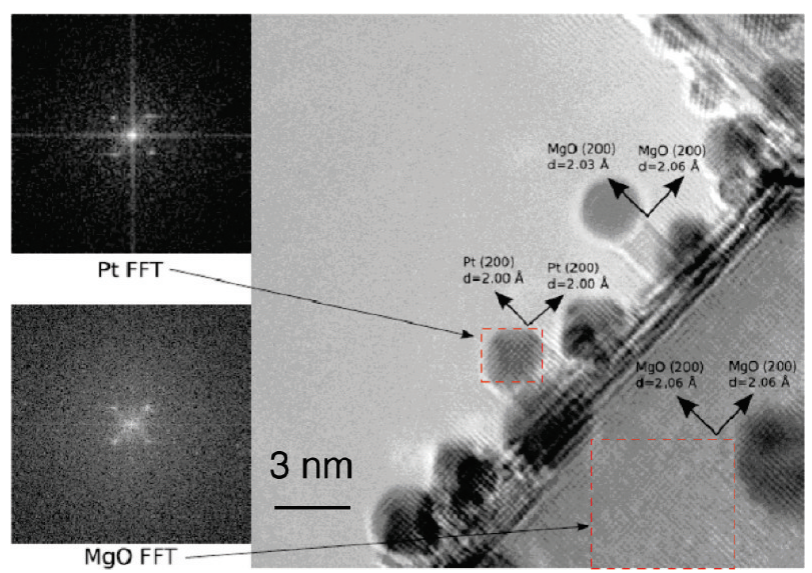

Figure 3. Lattice constants and orientations of the Pt particles and $\mathrm{MgO}$ crystals and nanorods indicating their epitaxial relationship. The image views both lattices in the (100) direction. The lattices of the $\mathrm{MgO}$ block and Pt particle were calculated from the Fourier transforms depicted on the left. The lattice constants of the $\mathrm{MgO}$ nanorod were measured directly from the image.

Under the electron beam irradiation, diffusion of $\mathrm{MgO}$ species $\left(\mathrm{O}^{+}, \mathrm{MgO}^{+}\right.$, and $\left.\mathrm{Mg}^{+}\right)$on the surface of a $\mathrm{MgO}$ crystal is relatively high. ${ }^{12}$ These ions can be attracted by negatively charged metal particles and trapped at the boundary between the particle and the $\mathrm{MgO}$. Here, the ions are discharged by the excessive electrons on the metal and start to build a crystallographic lattice epitaxially underneath the metal particle. The nanorod growth starts after some delay, as we observed, which is most likely due to the creation of the interface between the growing nanorod and the metal particle. It is worth noting that the charging and discharging processes are dynamic processes: the metal particle can be charged by trapping low energy secondary electrons emitted from $\mathrm{MgO}$ particles and can be discharged due to the interaction with positively charged ions. The rate of charging and discharging of a metal particle determines the rate of the nanorod growth. After the nanorod growth is initiated, there are two possible scenarios depending on the irradiation intensity. At high growth rates, the bottom of the metal particle is encapsulated inside the growing nanorod as shown in Figure 5, where a part of the Au particle detaches and gets trapped. At slow growth rates, the metal particle always remains on the top of the nanorod. The nanorod growth can be observed in a certain range of the beam intensities. The best growth conditions were obtained at the beam current density from 200 to $300 \mathrm{~A} / \mathrm{cm}^{2}$. 


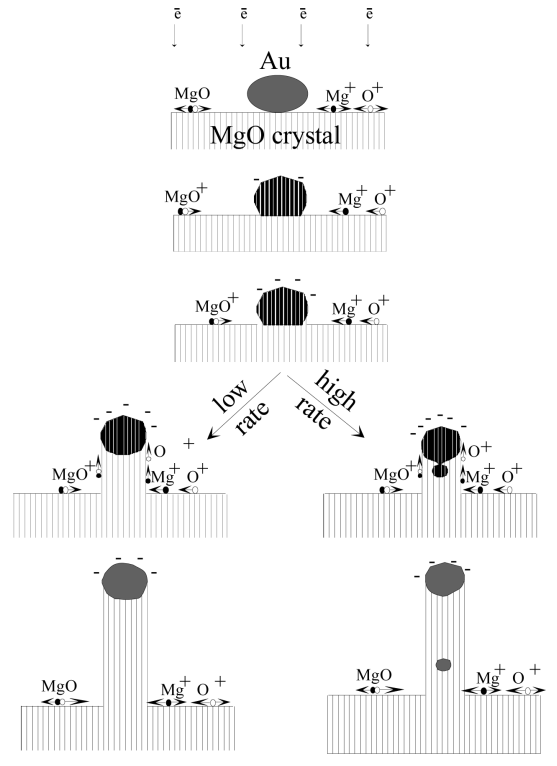

Figure 4. Proposed mechanism of $\mathrm{MgO}$ rod growth at low or high growth rate.

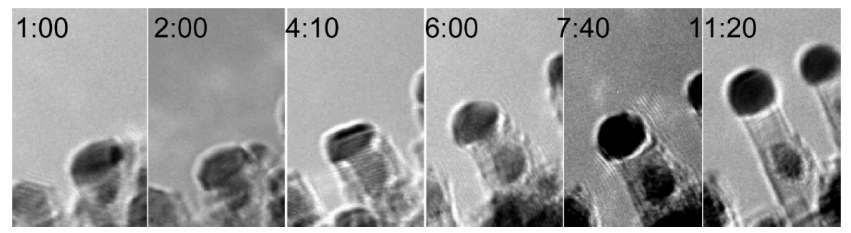

Figure 5. Growth of $\mathrm{MgO}$ nanorods by $\mathrm{Au}$ particles at room temperature. Part of the Au particle detaches and gets trapped inside the rod. Beam current density: around $200 \mathrm{~A} / \mathrm{cm}^{2}$. Each image represents an area of $9.4 \times 15.0 \mathrm{~nm}^{2}$ (Supporting Information, movie 1). The time from the start of the irradiation is displayed on each image (in min:sec).

Let us discuss the reason for termination of the nanorod growth when the length reaches $6-8 \mathrm{~nm}$. The Coulombic attraction between metal particle and ions on the crystal surface becomes weaker when the nanorod length increases and therefore the flux of building ions $\left(\mathrm{O}^{+}, \mathrm{MgO}^{+}\right.$, and $\left.\mathrm{Mg}^{+}\right)$ to the particles decreases. As a result, the nanorod growth is suppressed and the metal particle accumulates negative charges. This can lead to attraction of the metal to the positively charged $\mathrm{MgO}$ particle. Indeed, $\mathrm{Au}$ and $\mathrm{Pt}$ particles were observed to fall from the tip of the nanorod to the $\mathrm{MgO}$ particle and induce the growth of another nanorod, while the previously grown nanorod continuously disappears (Figure 6 and Supporting Information, movie S1). The termination of the nanorod growth was also observed due to the Ostwald ripening effect, ${ }^{22}$ when small particles vanish from the surface and even from the tip of the nanorods, while large particles become larger (Supporting Information, Figure S7 and movie S2).

In order to verify the importance of charging phenomena, we carried out experiments where the charging effect was partially suppressed. For this purpose, we irradiated $\mathrm{MgO}$ particles sitting close to the edge of a copper grid. In this arrangement, the charging of $\mathrm{MgO}$ can be suppressed because secondary electron emission from the massive grid discharges the $\mathrm{MgO}$ nanoparticles. This is a common technique to avoid charging of insulators in the electron beam of a TEM. Indeed, no nanorod growth was observed close to the copper grid,

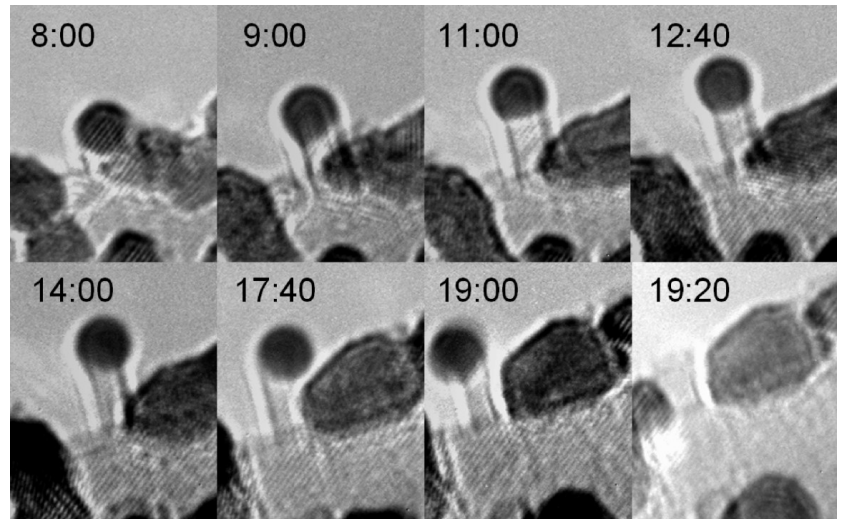

Figure 6. Growth of a $\mathrm{MgO}$ nanorod catalyzed by a Pt particle and termination due to the loss of the catalyst at room temperature $(200 \mathrm{kV})$. Each image represents an area of $9.2 \times 11.5 \mathrm{~nm}^{2}$. The time from the start of the irradiation is displayed on each image (in min:sec).

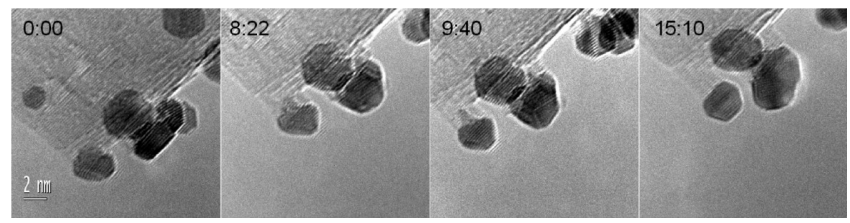

Figure 7. Growth of $\mathrm{MgO}$ nanorods by $\mathrm{Au}$ particles under electron irradiation at $-175^{\circ} \mathrm{C}(300 \mathrm{kV})$. Beam current density: $300 \mathrm{~A} / \mathrm{cm}^{2}$. Each image represents an area of $9.2 \times 9.2 \mathrm{~nm}^{2}$. The time from the start of the irradiation is displayed on each image (in min:sec).

confirming the electrical nature of the nanorod growth (Supporting Information, Figure S8).

It is important to note that $\mathrm{Fe}$ sputtered on the surface of $\mathrm{MgO}$ did not result in the growth of nanorods (Supporting Information, Figure S6). This can be explained by formation of iron oxide after taking the substrate with sputtered Fe to the ambient conditions. Iron oxide particles on the surface of the $\mathrm{MgO}$ crystal would not initiate the nanorod growth.

According to a possible thermal nature of $\mathrm{MgO}$ nanorod growth, it is worth noting that the growth was observed in the temperature range from -175 to $300{ }^{\circ} \mathrm{C}$. At higher temperatures, due to higher diffusion of atoms and small particles on the surface of $\mathrm{MgO}$, the nanorod growth was suppressed by the enhanced Ostwald ripening effect (Supporting Information, Figure S9). Metal particles with excessive size were not observed to induce the growth of nanorods. TEM observations showed that the particles shrink due to surface diffusion and finally disappear under long-time irradiation at $610^{\circ} \mathrm{C}$ (Supporting Information, Figure S10). TEM images illustrating the growth of $\mathrm{MgO}$ nanorods at $-175^{\circ} \mathrm{C}$ are shown in Figure 7. It is worth noting that this is the lowest temperature at which nanorods have been synthesized. The process of nanorod growth at this temperature is more stable (no drift or vibrating during the irradiation) than that at room temperature, and the growth rate seemed to be faster. Therefore, the growth of nanorods is not directly associated with the thermal energy. A considerable heating of these objects in the electron beam can be neglected due to the low contribution of inelastic scattering.

In conclusion, we investigated the growth of $\mathrm{MgO}$ nanorods under electron irradiation of $\mathrm{MgO}$ covered by $2-4 \mathrm{~nm}$ sized $\mathrm{Au}, \mathrm{Pt}, \mathrm{Ni}$, or Co particles. Growth of $\mathrm{MgO}$ nanorods was found at accelerating voltages from 120 to $300 \mathrm{kV}$ and in 
the temperature range from -175 to $300{ }^{\circ} \mathrm{C}$. At higher temperatures, the growth of nanorods was suppressed by overgrowth of metal particles due to the Ostwald ripening effect. Termination of $\mathrm{MgO}$ nanorod growth was found to occur due to the loss of metal particles. Fe did not result in the growth of nanorods due to the formation of iron oxide on the surface of a $\mathrm{MgO}$ crystal. The nanorod growth was explained on the basis of an electrostatic repulsion-attraction interaction mechanism.

Acknowledgment. The authors thank Mr. Prasnatha R. Mudimela for preparation of $\mathrm{MgO}$ samples. This work was supported by the Academy of Finland (Project Number 128445). S.D.S. thanks the European Commission for financial support through a Marie Curie Individual Fellowship (No. MIF1-CT-2005-022110). L.S. thanks the National Basic Research Programme of China (Grant No. 2006CB300404) and the National Natural Science Foundation of China (No. 60976003).

Supporting Information Available: (1) Characterization of $\mathrm{MgO}$ particles; (2) statistical measurements; (3) $\mathrm{Co}, \mathrm{Ni}$, and $\mathrm{Fe}$ as a catalyst; (4) Ostwald ripening effect; (5) nanorod growth near a copper grid; (6) electron irradiation at high temperatures; and (7) movies. This information is available free of charge via the Internet at http://pubs.acs.org/.

\section{References}

(1) Patolsky, F.; Timko, B. D.; Yu, G.; Fang, Y.; Greytak, A. B.; Zheng, G.; Lieber, C. M. Science 2006, 313, 1100-1104.
(2) Xiang, J.; Lu, W.; Hu, Y.; Wu, Y.; Yan, H.; Lieber, C. M. Nature 2006, 441, 489-493.

(3) Li, Y.; Qian, F.; Xiang, J.; Lieber, C. M. Mater. Today 2006, 9, 18-27.

(4) Zhao, M.; Chen, X. L.; Wang, W. J.; Ma, Y. J.; Xu, Y. P.; Zhao, H. Z. Mater. Lett. 2006, 60, 2017-2019.

(5) Ajayan, P. M.; Marks, L. D. Phys. Rev. Lett. 1989, 63, 279-282.

(6) Ajayan, P. M.; Marks, L. D. Nature 1989, 338, 139-141.

(7) Ajayan, P. M.; Iijima, S. J. Colloid Interface Sci. 1991, 147, 281285.

(8) Shashkov, D. A.; Chisholm, M. F.; Seidman, D. N. Acta Mater. 1999, 47, 3939-3951.

(9) Wang, C. M.; Shutthanandan, V.; Zhang, Y.; Thevuthasan, S.; Duscher, G. JASC 2005, 88, 3184-3191.

(10) Hoel, R. H. Surf. Sci. 1986, 169, 317-326.

(11) Giorgio, S.; Henry, C. R.; Chapon, C.; Nihoul, G.; Penisson, J. M. Utramicroscopy 1991, 38, 1-12.

(12) Kizuka, T. Jpn. J. Appl. Phys. 2001, 40, L1061-L1064.

(13) Chen, Y.; Li, J.; Han, Y.; Yang, X.; Dai, J. J. Cryst. Growth 2002, $245,163-170$

(14) Yang, Q.; Sha, J.; Wang, L.; Wang, J.; Yang, D. Mater. Sci. Eng. C 2006, 26, 1097-1101.

(15) Kim, H. W.; Shim, S. H. Chem. Phys. Lett. 2006, 422, 165-169.

(16) Nagashima, K.; Yanagida, T.; Tanaka, H.; Kawai, T. J. Appl. Phys. 2007, 101, 124304.

(17) Nagashima, K.; Yanagida, T.; Tanaka, H.; Kawai, T. Appl. Phys. Lett. 2007, 90, 233103.

(18) Marcu, A.; Yanagida, T.; Nagashima; Tanaka, H.; Kawai, T. J. Appl. Phys. 2007, 102, 016102.

(19) Altman, I. S.; Pikhitsa, P. V.; Choi, M.; Nasibulin, A. G.; Kauppinen, E. I. Phys. Rev. B 2003, 68, 125324.

(20) Whetten, N. R.; Laponsky, A. B. J. Appl. Phys. 1958, 30, 432-435.

(21) Williams, D. B.; Carter, C. B. Transmission Electron MicroscopyBasics; Plenum Press: New York, London, 1996.

(22) Hannon, J. B.; Kodambaka, S.; Ross, F. M.; Tromp, R. M. Nature 2006, 69-71. 